\title{
Role of Spousal Involvement in Continuous Positive Airway Pressure (CPAP) Adherence in Patients with Obstructive Sleep Apnea (OSA)
}

\author{
Salma Batool-Anwar, MD, MPH ${ }^{2}$ \\ Carol M. Baldwin, PhD, MSN ${ }^{3}$ \\ Shira Fass, $P h D^{4}$ \\ Stuart F. Quan, MD 1,2

\begin{abstract}
'University of Arizona College of Medicine, Tucson, AZ USA Brigham and Women's Hospital, Boston, MA USA

${ }^{3}$ Arizona State University College of Nursing and Health Innovation and College of Health Solutions, Phoenix, AZ USA

${ }^{4}$ Case Western Reserve University, Cleveland, Ohio USA
\end{abstract}

\begin{abstract}
Introduction: Little is known about the impact of spousal involvement on continuous positive airway pressure (CPAP) adherence. The aim of this study was to determine whether spouse involvement affects adherence with CPAP therapy, and how this association varies with gender.

Methods: 194 subjects recruited from Apnea Positive Pressure Long Term Efficacy Study (APPLES) completed the Dyadic Adjustment Scale (DAS). The majority of participants were Caucasian (83\%), and males (73\%), with mean age of 56 years, mean BMl of $31 \mathrm{~kg} / \mathrm{m}^{2}$. \& $62 \%$ had severe OSA. The DAS is a validated 32-item self-report instrument measuring dyadic consensus, satisfaction, cohesion, and affectional expression. A high score in the DAS is indicative of a person's adjustment to the marriage. Additionally, questions related to spouse involvement with general health and CPAP use were asked. CPAP use was downloaded from the device and self-report, and compliance was defined as usage $\geq 4 \mathrm{~h}$ per night.

Results: There were no significant differences in overall marital quality between the compliant and noncompliant subjects. However, level of spousal involvement was associated with increased CPAP adherence at 6 months $(p=0.01)$. After stratifying for gender these results were significant only among males $(p=0.03)$. Three years after completing APPLES, level of spousal involvement was not associated with CPAP compliance even after gender stratification.
\end{abstract}


Conclusion: Spousal involvement is important in determining CPAP compliance in males in the $1^{\text {st }} 6$ months after initiation of therapy but is not predictive of longerterm adherence. Involvement of the spouse should be considered an integral part of CPAP initiation procedures.

\section{Abbreviations List}

AASM: American Academy of Sleep Medicine

AHI: Apnea Hyponea Index

APPLES: Apnea Positive Pressure Long Term Efficacy Study

BMI: Body Mass Index

CPAP: Continuous positive airway pressure

DAS: Dyadic Adjustment Scale

EEG: Electroencephalogram

EMG: Electromyograms

EOG: Electroocculogram

OSA: Obstructive Sleep Apnea

PSG: polysomnography

\section{Introduction}

Obstructive Sleep apnea (OSA) is characterized by repetitive episodes of upper airway closure during sleep resulting in oxygen desaturation and frequent arousals. In addition to cardiovascular comorbidities, OSA has been linked to poor quality of life, depression and motor vehicle accidents. Recent data suggest an increase in the prevalence of OSA for both men and women (34\% and 17.4\% respectively) (1).

Continuous positive airway pressure (CPAP) is the treatment of choice for OSA. Poor adherence, however, remains a widely recognized problem limiting overall effectiveness of CPAP therapy. Prior studies have identified various factors and strategies to promote CPAP adherence (2). In addition to disease, educational, and technology-specific considerations that can affect CPAP adherence, social and psychological dynamics are important components of adherence as well.

Several studies have suggested that partner/spousal dyadic support can play a positive role in the patient's overall health and health behaviors $(3,4)$. For 
example, higher CPAP adherence was reported among patients with bed partners (5), as well as persons who were married versus single (6). Little is known about the influence of spousal involvement on CPAP adherence. One study indicated that perceived spousal support predicted greater CPAP adherence among men with high disease severity; however, pressure to adhere to treatment by the wife was not of benefit and predicted poorer CPAP adherence (7). Another study indicated reduced marital conflict by OSA patients following 3 months of CPAP, suggesting that marital conflict resolution might serve as an intervention for CPAP adherence (8). Despite these hints that dyadic support may play a role in CPAP adherence, participants in both studies by Baron et al. (7.8) consisted primarily of men, and the studies focusing on CPAP adherence by Lewis et al. (5) and Gagnadoux et al. (6) included only men. Thus, the aim of the current study was to determine whether spouse involvement affects CPAP adherence and how this association differs by gender using data from a large randomized trial of CPAP versus sham CPAP to treat OSA.

\section{Methods}

\section{Study Population and Protocol}

The Apnea Positive Pressure Long-term Efficacy Study (APPLES) was a 6-month multicenter, randomized, double-blinded, 2-arm, sham-controlled, intention-to-treat study of CPAP efficacy on three domains of neurocognitive function in OSA. Three of the 5 APPLES Clinical Centers, the University of Arizona, Stanford University and St. Luke's Hospital (Chesterfield, MO) participated in this ancillary study. A detailed description of the protocol has previously been published (9). Briefly, participants were either recruited through local advertisement, or from attending sleep clinics for evaluation of possible OSA. Symptoms indicative of OSA were used to prescreen potential participants. The initial clinical evaluation included administering informed consent, screening questionnaires, a history and physical examination, and a medical assessment by a study physician. Participants subsequently returned 2-4 weeks later for a 24-h sleep laboratory visit, during which polysomnography (PSG) was performed to confirm the diagnosis, followed by a day of neurocognitive, mood, sleepiness, and quality of life survey testing. Inclusion and exclusion criteria have been published previously and included age $\geq 18$ years and a clinical diagnosis of OSA as defined by American Academy of Sleep Medicine (AASM) criteria. Only participants with an apnea hypopnea index 
$(\mathrm{AHI}) \geq 10$ by PSG were randomized to continue in the APPLES study. Exclusion criteria were previous treatment for OSA with CPAP or surgery, oxygen saturation on baseline $P S G<75 \%$ for $>10 \%$ of the recording time, history of motor vehicle accident-related to sleepiness within the past 12 months, presence of chronic medical conditions, use of various medications known to affect sleep or neurocognitive function, and various health and social factors that may impact standardized testing procedures (e.g., shift work).

Following the $\mathrm{PSG}$, participants with an $\mathrm{AHI} \geq 10$ who met other enrollment criteria were randomized to CPAP or sham CPAP for continued participation in APPLES. After randomization, participants returned to the sleep laboratory for a CPAP or sham CPAP titration PSG. Subsequent assessments were made at 2, and 6 months post-randomization at which time a test battery was re-administered. At the conclusion of their 6-month post-randomization evaluations, each participant was informed of their treatment group assignment and offered CPAP treatment going forward. Approximately 36 months after the conclusion of APPLES, participants were sent the Dyadic Adjustment Scale (DAS) questionnaire with the addition of several additional questions related to health.

\section{Assessment of Spouse involvement}

Inclusion in the current analysis required that subjects were married during the APPLES study and remained married at the time of questionnaire administration. The DAS (10), a quality of marriage questionnaire, was utilized to assess marital relationship. It is a 32-item self-report instrument that incorporates four dimensions, including a 13 item dyadic consensus, 10 item dyadic satisfaction, 5 item dyadic cohesion, and 4 item affectional expression. A high DAS score is indicative of a person's positive adjustment to the marriage. Additionally, questions related to spouse involvement with general health and CPAP use were asked (See Appendix for full questionnaire).

\section{Polysomnography}

The PSG montage included monitoring of the electroencephalogram (EEG, $\mathrm{C}_{3}-$ $A_{2}$ or $C_{4}-A_{1}, O_{2}-A_{1}$ or $O_{1}-A_{2}$ ), electro-oculogram (EOG, ROC-A $A_{1}, L O C-A_{2}$ ), chin and anterior tibialis electromyograms (EMG), heart rate by 2-lead electrocardiogram, snoring intensity (anterior neck microphone), nasal pressure (nasal cannula), nasal/oral thermistor, thoracic and abdominal movement (inductance 
plethysmography bands), and oxygen saturation (pulse oximetry). All PSG records were electronically transmitted to a centralized data coordinating and PSG reading center. Sleep and wakefulness were scored using Rechtschaffen and Kales criteria (11). Apneas and hypopneas were scored using American Academy of Sleep Medicine Task Force (1999) diagnostic criteria (12,13). Briefly, an apnea was defined by a clear decrease (>90\%) from baseline in the amplitude of the nasal pressure or thermistor signal lasting $\geq 10 \mathrm{sec}$. Hypopneas were identified if there was a clear decrease (> $50 \%$ but $\leq 90 \%$ ) from baseline in the amplitude of the nasal pressure or thermistor signal, or if there was a clear amplitude reduction of the nasal pressure signal $\geq 10 \mathrm{sec}$ that did not reach the above criterion, but was associated with either an oxygen desaturation $>3 \%$ or an arousal.

Obstructive events were scored if there was persistence of chest or abdominal respiratory effort. Central events were noted if no displacement occurred on either the chest or abdominal channels. Sleep apnea was classified as mild (AHI 10.0 to 15.0 events per hour), moderate (AHI 15.1 to 30.0 events per hour), and severe (AHI more than 30 events per hour) (12).

\section{CPAP adherence}

The primary dependent variable of interest was CPAP adherence and was assessed by nightly use of CPAP at the 6-months follow up visit. CPAP use was downloaded from the device and the participants were considered to be adherent if the mean CPAP use was $>4$ hours per night at 6-months. Long-term CPAP adherence was measured as self-reported adherence (hours per night) at the time of the DAS administration.

\section{Statistical Analysis}

Statistical analyses were performed using STATA (Version 11, StataCorp TX USA). Univariate and multivariate logistic regression models were used to estimate the degree to which variables correlated with CPAP adherence. We examined the association between CPAP adherence and following variables: OSA severity as measured by the $A H I$, age, baseline body mass index (BMI, $\left.\mathrm{kg} / \mathrm{m}^{2}\right)$, spousal involvement and the DAS. For these models, dichotomous variables were created for OSA severity (AHI $<15 \mathrm{vs.} \geq 15$ ), obesity (BMI $<30 \mathrm{~kg} / \mathrm{m}^{2} \mathrm{vs.} \geq 30$ $\mathrm{kg} / \mathrm{m}^{2}$ ) and CPAP adherence ( $<4$ hours/night vs. $\geq 4$ hours/night). Spousal 
involvement was ascertained using a 5 point Lickert scale and analyzed as a continuous variable.

To assess predictors of CPAP adherence we used multiple regression models. Unpaired t-tests were used to assess the effect of gender, age, OSA severity, BMI, and CPAP adherence in both the CPAP and Sham CPAP groups. Data for continuous and interval variables were expressed as mean $\pm S D$, and as a percentage for categorical variables. Statistical significance was set at a $P$ value $<0.05$, two-tailed. The variables that produced $P$ value of $<0.05$ were included in the final model.

\section{Results}

Baseline demographic data on participants $(\mathrm{N}=194)$ who completed the DAS are outlined in Table 1.

Table1. Baseline Characteristics of APPLES Participants Who Completed Dyadic Data.

\begin{tabular}{|l|l|l|l|l|}
\hline & \multicolumn{2}{|c|}{$\begin{array}{c}\text { Compliant } \\
N=82\end{array}$} & \multicolumn{2}{c|}{$\begin{array}{c}\text { Non Compliant } \\
N=112\end{array}$} \\
\hline & $\begin{array}{c}\text { Sham } \\
N=28\end{array}$ & $\begin{array}{c}\text { CPAP } \\
N=54\end{array}$ & $\begin{array}{c}\text { Sham } \\
N=56\end{array}$ & \multicolumn{1}{c|}{$\begin{array}{c}\text { CPAP } \\
N=56\end{array}$} \\
\hline White (\%) & $23(82)$ & $44(81)$ & $46(82)$ & $49(87)$ \\
\hline Age (SD) & $\begin{array}{l}59.6 \\
(9.9)\end{array}$ & $59(8.7)$ & $53(10.5)$ & $53(10)$ \\
\hline Males (\%) & $19(68)$ & $45(83)$ & $39(69)$ & $40(71)$ \\
\hline Mild (\%) & $5(18)$ & $10(18.5)$ & $7(12.5)$ & $7(12.5)$ \\
\hline Moderate (\%) & $7(25)$ & $10(18.5)$ & $12(21)$ & $16(29)$ \\
\hline Severe (\%) & $16(57)$ & $34(63)$ & $37(66)$ & $33(59)$ \\
\hline BMI (SD) & $31(6.9)$ & $31.3(5.2)$ & $32(7.7)$ & $31.4(6.6)$ \\
\hline
\end{tabular}

SD: standard deviation, BMI: Body Mass Index,

The majority of the participants were Caucasian (83\%) and males (73\%), with mean age of 56 years and a mean BMI of $31 \mathrm{~kg} / \mathrm{m}^{2}$. Over half of the participants 
had severe OSA (62\%). Table 2a demonstrates CPAP adherence at 6 months using multivariate analysis.

Table 2A. Multivariate Analysis of Adherence to CPAP or Sham CPAP at 6 Months.

\begin{tabular}{|l|c|c|c|}
\hline & $\begin{array}{c}\text { overall coefficient } \\
(p \text {-value })\end{array}$ & $\begin{array}{c}\text { Coefficient for } \\
\text { Men } \\
(p \text {-value })\end{array}$ & $\begin{array}{c}\text { Coefficient for Women } \\
(p \text {-value })\end{array}$ \\
\hline Spouse involvement & $\begin{array}{c}0.07 \\
(0.01)^{*}\end{array}$ & $\begin{array}{c}0.088 \\
(0.03)^{*}\end{array}$ & $\begin{array}{c}0.08 \\
(0.19)\end{array}$ \\
\hline Age & $\begin{array}{c}0.015 \\
(0.0001)^{*}\end{array}$ & $\begin{array}{c}0.012 \\
(0.002)^{*}\end{array}$ & $\begin{array}{c}0.02 \\
(0.003)^{*}\end{array}$ \\
\hline OSA & -0.09 & -0.07 & -0.18 \\
\hline BMI & $(0.06)$ & $(0.25)$ & $(0.07)$ \\
\hline Gender & $\begin{array}{c}0.007 \\
(0.23)\end{array}$ & $\begin{array}{c}0.004 \\
(0.55)\end{array}$ & $\begin{array}{c}0.012 \\
(0.14)\end{array}$ \\
\hline
\end{tabular}

BMI: Body Mass Index, OSA: Obstructive Sleep Apmea, $* P \leq 005$

The CPAP adherence was independently associated with advanced age $(p<0.01)$ and increasing spousal involvement $(p<0.01)$. After stratifying by treatment group, the association between CPAP adherence and spousal involvement was seen only amongst the CPAP group (Table $2 b$ ).

Table 2B. Multivariate Analysis of Adherence to CPAP at 6 Months. 


\begin{tabular}{|l|c|c|c|}
\hline Spouse involvement & $\begin{array}{c}\text { overall coefficient } \\
(p \text {-value })\end{array}$ & $\begin{array}{c}\text { Coefficient for } \\
\text { Men } \\
(\rho \text {-value })\end{array}$ & $\begin{array}{c}\text { Coefficient for Women } \\
(\rho \text {-value })\end{array}$ \\
\hline Age & 0.11 & 0.13 & 0.08 \\
& $(0.01)$ & $(0.01)^{*}$ & $(0.43)$ \\
\hline & 0.02 & 0.02 & 0.02 \\
OSA & $(0.003)$ & $(0.006)^{*}$ & $(0.25)$ \\
\hline & -0.09 & -0.07 & -0.12 \\
BMI & $(0.18)$ & $(0.31)$ & $0.59)$ \\
\hline & 0.01 & 0.01 & 0.01 \\
Gender & $(0.29)$ & $(0.47)$ & \\
\hline
\end{tabular}

BMI: Body Mass Index, OSA: Obstructive Sleep Apmea, $* P<005$

Adjustment to marriage as reflected by items on the DAS questionnaire, however, was not associated with CPAP adherence.

Notably, after gender stratification, significant association between spousal involvement and CPAP adherence was limited to men alone $(p=0.03)$. Three years after completing APPLES, 82 participants were still adherent by self-report (Table 3).

Table 3. Multivariate Analysis CPAP Adherence 3 years After Completing APPLES Study (based on subjective adherence).

\begin{tabular}{|l|c|c|c|}
\hline & $\begin{array}{c}\text { Overall coefficient } \\
(p \text {-value) }\end{array}$ & $\begin{array}{c}\text { Coefficient for } \\
\text { Men } \\
\text { (p-value) }\end{array}$ & $\begin{array}{c}\text { Coefficient for Women } \\
\text { ( } p \text {-value) }\end{array}$ \\
\hline Spouse involvement & $\begin{array}{c}0.15 \\
(0.13)\end{array}$ & $\begin{array}{c}0.15 \\
(0.21)\end{array}$ & $\begin{array}{c}0.21 \\
(0.38)\end{array}$ \\
\hline Age & $\begin{array}{c}0.01 \\
(0.57)\end{array}$ & $\begin{array}{c}0.01 \\
(0.52)\end{array}$ & $\begin{array}{c}0.001 \\
(0.97)\end{array}$ \\
\hline OSA & -0.3 & -0.26 & -0.4 \\
\hline BMI & $(0.06)$ & $(0.17)$ & $(0.31)$ \\
\hline Gender & 0.015 & $0.01(0.67)$ & 0.016 \\
\hline
\end{tabular}

BMI: Body Mass Index, OSA: Obstructive Sleep Apmea 
At this time point, spousal involvement was not associated with CPAP adherence even after gender stratification.

\section{Discussion}

This multicenter double blind study demonstrates that spousal involvement is important in determining CPAP adherence during the initial treatment period, but has no effect on long-term adherence. Notably, the positive results for adherence were seen only among husbands using CPAP, but there was no effect on wives using CPAP. In line with previous research, we also found that increase in age was associated with greater CPAP adherence among both men and women. Prior studies have indicated that married versus single, CPAP patients with bed partners, perceived spousal support, and quality of marital relationship all play a role in promoting CPAP adherence (5-8). Although these studies support the idea of social support as a conduit to CPAP adherence, the role of spousal involvement was not clear, sample sizes in the spousal role studies were small, and CPAP users were men, which reduces generalizability.

Baron et al. (3) used a spousal involvement measure, including positive and negative collaboration and one-sided items one week after beginning CPAP treatment ( $\mathrm{N}=23$ married men on CPAP), in addition to an interpersonal measure of supportive behaviors at 3 months to evaluate interpersonal qualities ( $n=16 / 23$ responded). These investigators found that perceived collaborative involvement was related to greater CPAP adherence at 3 months $(p=0.002)$. These findings are similar to our study in that spousal support, at least for husbands on CPAP, fostered greater adherence during the initial period of treatment.

Our observations and those of Baron et al. (14) fit well with the theories of motivation. The fundamental fact of motivation and adherence in healthcare is that individuals cannot be forced to change their behaviors. The behavior change, in this case the CPAP adherence, may be initiated by extrinsic motivation. External motivation may be rewards, punishments, or pressure from other people, such as family members or healthcare providers. However, extrinsic motivation, such as spousal pressure, is less effective in the long-term. In order to sustain long term behavioral change for CPAP adherence one needs to rely on intrinsic motivation 
which can be strengthened by examining the decisional balance of the ratio between a patient's perceived pros and cons for engaging in a health behavior. The decisional balance has been found to be predictive of adherence to treatment in a variety of healthcare settings.

Our study also found increased age as an independent predictor of CPAP adherence at 6-months, yet the results were not significant for long-term adherence. Previous studies have also demonstrated conflicting results on the association between age and CPAP adherence. Sin et al. (15) found that a 10 year increment in age resulted in $0.24 \pm 0.11$-h increase in CPAP use. Alternatively, McArdle and colleagues (16) found that older patients were less likely to use their CPAP machines. Similarly, Janson et al. (17) found older age to be an independent risk factor for discontinuing CPAP treatment, and this finding was thought to be secondary to nasal, or pharyngeal problems. In another study, Russo-Magno et al. (18) found that adherent patients were younger in age compared to non-adherents, and increasing age made CPAP adherence difficult. Cognitive and physical impairments were thought to be contributing to difficulty with CPAP adherence. Mean age in this cohort was 73 years, which was higher than the mean age in our study. It is possible that these inconsistent associations of age on CPAP adherence may be related to the length of follow-up as well. With longer durations, the effect of time on comorbidities in the elderly may make adherence more difficult.

To our knowledge, this is the first study to demonstrate a gender bias in support for CPAP adherence. While men on CPAP were significantly more likely to adhere with support from their wives, there was no such effect for married women on CPAP, suggesting little to no support from their husbands. Although the effect of gender on CPAP adherence and spousal involvement has not been studied, previous research suggests that women are more likely to be the health caregivers in families, and thus exercise more social control (19). It is the social norm and expectation that women are often involved in their husbands' health. As indicated in the literature regarding type 2 diabetes (20), male patients and their wives shared an expectation that the wives will be involved in their care while female patients and their husbands did not have similar expectations. We can support this finding in relationship to CPAP adherence. 
Not surprisingly, spousal support for adherence did not apply to sham CPAP. This suggests that if an intervention is not having any perceived benefit, spousal involvement will have little impact on adherence.

There are several limitations to this study. A major limitation is self-reported long term CPAP adherence. Additionally, our study was limited to husbands and wives on CPAP completing the DAS; their respective spouses were not asked about their degree of involvement. Moreover, it is unclear which components of spouse involvement played a role in CPAP adherence. We cannot assume that patients welcome all types of spouse involvement. Spouse involvement may be perceived by patients as control and nagging and may not be advantageous for all patients (21). In the context of chronic illness significant differences are demonstrated across couples in expectations for spouse involvement (20).

Despite these limitations, to our knowledge this is the first study of its type that examined spousal support for both men and women on CPAP supporting generalizability of our findings. Other strengths of this study include a large number of participants across multiple sites, randomized CPAP and Sham CPAP control groups, and objective documentation of CPAP adherence at 6 months. Dyadic coping has been utilized in other health related interventions and can also be used to improve CPAP adherence. Ye et al. (4) has provided a comprehensive review of dyadic support in CPAP adherence, including methodological considerations, recommendations for future research, and implications for interventions. In tandem with the Ye et al. (4) review, our findings, particularly with respect to the need for spousal support of wives on CPAP, can provide a springboard for future clinical/intervention studies to promote CPAP adherence for men and women, to develop gender-relevant training needs to support their spouse on CPAP, and to determine spousal support activities that are the most efficient at promoting CPAP adherence.

\section{Acknowledgments}

APPLES was funded by contract 5UO1-HL-068060 from the National Heart, Lung and Blood Institute. The APPLES pilot studies were supported by grants from the American Academy of Sleep Medicine and the Sleep Medicine Education and Research Foundation to Stanford University and by the National Institute of 
Neurological Disorders and Stroke (N44-NS-002394) to SAM Technology. In addition, APPLES investigators gratefully recognize the vital input and support of Dr. Sylvan Green who died before the results of this trial were analyzed, but was instrumental in its design and conduct.

\section{Administrative Core}

Clete A. Kushida, MD, PhD; Deborah A. Nichols, MS; Eileen B. Leary, BA, RPSGT; Pamela R. Hyde, MA; Tyson H. Holmes, PhD; Daniel A. Bloch, PhD; William C. Dement, MD, PhD

\section{Data Coordinating Center}

Daniel A. Bloch, PhD; Tyson H. Holmes, PhD; Deborah A. Nichols, MS; Rik Jadrnicek, Microflow, Ric Miller, Microflow Usman Aijaz, MS; Aamir Farooq, PhD; Darryl Thomander, PhD; Chia-Yu Cardell, RPSGT; Emily Kees, Michael E. Sorel, MPH; Oscar Carrillo, RPSGT; Tami Crabtree, MS; Booil Jo, PhD; Ray Balise, $\mathrm{PhD}$; Tracy Kuo, PhD

\section{Clinical Coordinating Center}

Clete A. Kushida, MD, PhD, William C. Dement, MD, PhD, Pamela R. Hyde, MA, Rhonda M. Wong, BA, Pete Silva, Max Hirshkowitz, PhD, Alan Gevins, DSc, Gary Kay, PhD, Linda K. McEvoy, PhD, Cynthia S. Chan, BS, Sylvan Green, MD

\section{Clinical Centers}

Stanford University

Christian Guilleminault, MD; Eileen B. Leary, BA, RPSGT; David Claman, MD; Stephen Brooks, MD; Julianne Blythe, PA-C, RPSGT; Jennifer Blair, BA; Pam Simi, Ronelle Broussard, BA; Emily Greenberg, MPH; Bethany Franklin, MS; Amirah Khouzam, MA; Sanjana Behari Black, BS, RPSGT; Viola Arias, RPSGT; Romelyn Delos Santos, BS; Tara Tanaka, PhD University of Arizona Stuart F. Quan, MD; James L. Goodwin, PhD; Wei Shen, MD; Phillip Eichling, MD; Rohit Budhiraja, MD; Charles Wynstra, MBA; Cathy Ward, Colleen Dunn, BS; Terry Smith, BS; Dane Holderman, Michael Robinson, BS; Osmara Molina, BS; Aaron Ostrovsky, Jesus Wences, Sean Priefert, Julia Rogers, BS; Megan Ruiter, BS; Leslie Crosby, BS, RN 


\section{St. Mary Medical Center}

Richard D. Simon Jr., MD; Kevin Hurlburt, RPSGT; Michael Bernstein, MD;

Timothy Davidson, MD; Jeannine Orock-Takele, RPSGT; Shelly Rubin, MA; Phillip Smith, RPSGT; Erica Roth, RPSGT; Julie Flaa, RPSGT; Jennifer Blair, BA; Jennifer Schwartz, BA; Anna Simon, BA; Amber Randall, BA

St. Luke's Hospital James K. Walsh, PhD, Paula K. Schweitzer, PhD, Anup Katyal, MD, Rhody Eisenstein, MD, Stephen Feren, MD, Nancy Cline, Dena Robertson, RN, Sheri Compton, RN, Susan Greene, Kara Griffin, MS, Janine Hall, PhD Brigham and Women's Hospital Daniel J. Gottlieb, MD, MPH, David P. White, MD, Denise Clarke, BSc, RPSGT, Kevin Moore, BA, Grace Brown, BA, Paige Hardy, MS, Kerry Eudy, PhD, Lawrence Epstein, MD, Sanjay Patel, MD

*Sleep HealthCenters for the use of their clinical facilities to conduct this research

\section{Consultant Teams}

Methodology Team: Daniel A. Bloch, PhD, Sylvan Green, MD, Tyson H. Holmes, PhD, Maurice M. Ohayon, MD, DSc, David White, MD, Terry Young, PhD Sleep-Disordered Breathing Protocol Team: Christian Guilleminault, MD, Stuart Quan, MD, David White, MD EEG/Neurocognitive Function Team: Jed Black, MD, Alan Gevins, DSc, Max Hirshkowitz, PhD, Gary Kay, PhD, Tracy Kuo, PhD Mood and Sleepiness Assessment Team: Ruth Benca, MD, PhD, William C. Dement, MD, PhD, Karl Doghramji, MD, Tracy Kuo, PhD, James K. Walsh, PhD Quality of Life Assessment Team: W. Ward Flemons, MD, Robert M. Kaplan, PhD APPLES Secondary Analysis-Neurocognitive (ASA-NC) Team: Dean Beebe, PhD, Robert Heaton, PhD, Joel Kramer, PsyD, Ronald Lazar, PhD, David Loewenstein, PhD, Frederick Schmitt, PhD

\section{National Heart, Lung, and Blood Institute (NHLBI)}

Michael J. Twery, PhD, Gail G. Weinmann, MD, Colin O. Wu, PhD

\section{Data and Safety Monitoring Board (DSMB)}

Seven year term: Richard J. Martin, MD (Chair), David F. Dinges, PhD, Charles F. Emery, PhD, Susan M. Harding MD, John M. Lachin, ScD, Phyllis C. Zee, MD, $\mathrm{PhD}$

Other term: Xihong Lin, PhD (2 yrs), Thomas H. Murray, PhD (1 yr) 


\section{References}

1. Peppard PE, Young T, Barnet JH, Palta M, Hagen EW, Hla KM. Increased prevalence of sleep-disordered breathing in adults. Am J Epidemiol. 2013;177(9):1006-14. [CrossRef] [PubMed]

2. Sawyer AM, Gooneratne NS, Marcus CL, Ofer D, Richards KC, Weaver TE. A systematic review of CPAP adherence across age groups: clinical and empiric insights for developing CPAP adherence interventions. Sleep Med Rev. 2011;15(6):343-56. [CrossRef] [PubMed]

3. Baron KG, Gunn HE, Czajkowski LA, Smith TW, Jones CR. Spousal involvement in CPAP: does pressure help? J Clin Sleep Med. 2012;8(2):147-53. [CrossRef] [PubMed]

4. Ye L, Malhotra A, Kayser K, et al. Spousal involvement and CPAP adherence: A dyadic perspective. Sleep Med Rev. 2015;19:67-74. [CrossRef] [PubMed]

5. Lewis KE, Seale L, Bartle IE, Watkins AJ, Ebden P. Early predictors of CPAP use for the treatment of obstructive sleep apnea. Sleep. 2004; 27(1):134-8. [CrossRef] [PubMed]

6. Gagnadoux F, Le Vaillant M, Goupil F, et al. Influence of marital status and employment status on long-term adherence with continuous positive airway pressure in sleep apnea patients. PLoS One.6(8):e22503. [CrossRef] [PubMed]

7. Baron KG, Smith TW, Berg CA, Czajkowski LA, Gunn H, Jones CR. Spousal involvement in CPAP adherence among patients with obstructive sleep apnea. Sleep Breath. 2011;15(3):525-34. [CrossRef] [PubMed]

8. Baron KG, Smith TW, Czajkowski LA, Gunn HE, Jones CR. Relationship quality and CPAP adherence in patients with obstructive sleep apnea. Behav Sleep Med. 2009;7(1):22-36. [CrossRef] [PubMed]

9. Kushida CA, Nichols DA, Quan SF, et al. The apnea positive pressure long-term efficacy study (APPLES): rationale, design, methods, and procedures. J Clin Sleep Med. 2006; 2(3):288-300. [PubMed]

10. Carey MP, Spector IP, Lantinga LJ, Krauss DJ. Reliability of the dyadic adjustment scale. Psychol Assessment. 1993;5(2):238. [CrossRef] [PubMed]

11. Rechtschaffen A, Kales A. A manual of standardized terminology, techniques and scoring system for sleep stages of human subjects. Bethesda, Md., U. S. National Institute of Neurological Diseases and Blindness, Neurological Information Network, 1968.

12. Flemons WW, Buysse D, Redline S, Pack A. The report of American academy of sleep medicine task force. Sleep related breathing disorders in adults: 
recommendations for syndrome definition and measurement techniques in clinical research. Sleep. 1999;22(5):667-89. [CrossRef] [PubMed]

13. Quan SF, Gillin JC, Littner MR, Shepard JW. Sleep-related breathing disorders in adults: Recommendations for syndrome definition and measurement techniques in clinical research. editorials. Sleep. 1999;22(5):662-89. [CrossRef] [PubMed]

14. Prochaska JO, DiClemente CC. Transtheoretical therapy: Toward a more integrative model of change. Psychother-Theor Res. 1982;19(3):276. [CrossRef]

15. Sin DD, Mayers I, Man GCW, Pawluk L. Long-term compliance rates to continuous positive airway pressure in obstructive sleep apnea: a population-based study. CHEST. 2002;121(2):430-5. [PubMed]

16. McArdle N, Kingshott R, Engleman HM, Mackay TW, Douglas NJ. Partners of patients with sleep apnoea/hypopnoea syndrome: effect of CPAP treatment on sleep quality and quality of life. Thorax. 2001;56(7):513-8. [CrossRef] [PubMed]

17. Janson C, Nöges E, Svedberg-Brandt S, Lindberg E. What characterizes patients who are unable to tolerate continuous positive airway pressure (CPAP) treatment? Respir Med. 2000; 94(2): 145-9. [CrossRef] [PubMed]

18. Russo-Magno P, O'Brien A, Panciera T, Rounds S. Compliance with CPAP therapy in older men with obstructive sleep apnea. J Am Geriatr Soc. 2001;49(9):1205-11. [CrossRef] [PubMed]

19. Umberson D. Gender, marital status and the social control of health behavior. Soc Sci Med. 1992;34(8):907-17. [CrossRef] [PubMed]

20. Seidel AJ, Franks MM, Stephens MAP, Rook KS. Spouse control and type 2 diabetes management: moderating effects of dyadic expectations for spouse involvement. Fam Relat. 2012; 61(4):698-709. [CrossRef] [PubMed]

21. Tucker JS. Health-related social control within older adults' relationships. J of Gerontol B: Psychol Sci Soc Sci. 2002;57(5):P387-P395. [PubMed] 